\title{
TOURIST DESTINATION STRENGHTS AND OPPORTUNITIES: IS MONTENEGRO READY FOR CHINESE TOURISTS?
}

\author{
Ana Stranjančević \\ Mediterranean University, Faculty of Tourism in Podgorica, Montenegro \\ Iva Bulatović \\ Mediterranean University, Faculty of Tourism in Podgorica, Montenegro \\ Darko Lacmanović \\ Mediterranean University, Faculty of Tourism in Podgorica, Montenegro \\ Andrej Raspor \\ School of Advanced Social Studies in Nova Gorica, Slovenia
}

\section{SUMMARY}

Since Chinese outbound tourism currently represents the largest outbound tourist market, the opportunities for tourism of Montenegro in the Chinese tourist market should be certainly examined.

The aim of this paper is to analyze the relevant data about Chinese tourists who are visiting Montenegro: their specific demographic characteristics, travel habits and main motivation, but also to identify the possible ways to increase the number of Chinese tourists in Montenegro in future.

For the purpose of this paper, two years long empirical research was conducted among Chinese tourists in Montenegro with the help of questionnaire. Several interviews with representatives of tourism sector in Montenegro were carried out as well.

The authors have concluded that only after the total adjustment of Montenegro tourist offer to the Chinese tourists' preferences, Montenegro could be completely ready for intensive acceptance of Chinese tourists. What's more, in order to attract larger number of Chinese tourists, the effective marketing policy of Montenegro as a tourist destination should be created in that direction and as well the specialized tourism promotion at the Chinese market should be carried out.
Keywords: China, Montenegro, Tourism, Destination, Chinese tourists.

\section{INTRODUCTION}

As nowadays Chinese outbound tourism has significant role in global tourist market, it is very important for every tourist destination that, in its development strategy, pays adequate attention to this growing, long-distance tourist market. Therefore, considering the fact that tourism is the most important industry in Montenegro and, from the other side, that the number of Chinese tourists on the global level is significantly growing, Chinese tourist market is recognized as a great challenge for tourism industry of Montenegro. Accordingly, the first scientific empirical research dedicated to Chinese tourist market in Montenegro has been conducted, analyzing the characteristics of tourists from China who have already visited Montenegro, but also identifying the models to motivate potential Chinese tourists to come to this country in future.

According to the World Travel \& Tourism Council Investment Report, in the period from 2011 to 2021 Travel \& Tourism in Montenegro is expected to attract capital investment, which will be rising by $16.4 \%$ annually, what is the highest annual growth in the world, second only to Brazil. This means that Travel \& Tourism's share of total invest- 
ment in Montenegro will rise from 33.4\% in 2011 to $50.8 \%$ in 2021 , which indicates on the great importance of the tourism industry in economy of Montenegro.

The future success of this the most important industry in Montenegro will depend on the improvement of the existing tourist markets, but also on the identifying new target groups in tourism of Montenegro. One of them should certainly be a Chinese tourist market.

In order to examine the readiness of Montenegro as tourist destination for Chinese tourists empirical research was conducted which methodology, sample and results will be presented in this paper. The aim of this paper is to analyze the relevant data about Chinese tourists who are visiting Montenegro: number of tourist arrivals, overnight stays and their average stay; then their specific demographic characteristics, travel habits and main motivation for visiting Montenegro; but also to identify the possible ways to increase the number of Chinese tourists in Montenegro in future. In this empirical research are indeed determined important findings regarding both the tourist offer and tourist demand, which will be useful for decision-makers and creators of tourism and marketing policies in Montenegro.

The role and significance of the China at the global economy nowadays is changing and becoming more and more important in many aspects. China has become one of the key players in the world economy, as in 2010 it was the second economy on the world, after the United States of America (Lim and Pan, 2003). According to Rakotonanahary (2014), thanks to the real GDP growth rates of 10 percent for the past three decades, China is the world's fastest growing economy (Barnet, 2013). Although, the World Bank expects Chinese real GDP growth to ease slightly in the coming years, to about $6.7 \%$ in 2016 and $6.5 \%$ in 2017 , due to gradual rebalancing from investment to consumption and rapid rebalancing from industrial sector to services (Hofman, 2016), China's economy will still maintain its important place.
On the other hand, China has the world's largest population with 1.35 billion people, which could be the great potential for the outbound travel industry. Furthermore, as a result of a continued increase in leisure time and household income, during the past 20 years there is a remarkable increase of the number of Chinese tourists who travel abroad (Rakotonanahary, 2014). While UNWTO in 2003 predicted that about 100 million Chinese tourists are expected to travel abroad by 2020, according to Artl, 2016 (Bofulin et al., 2016), the number of Chinese tourists increased to 133 million even in the year of 2015. That's why nowadays there are more and more studies dedicated to Chinese outbound tourism in order to identify the most appropriate tourism strategies for this emerging tourist market.

Due to the significant economic rise of China, many authors observe the role of this new emerging economy. As Cox (2012) state, some of them point out that China is fast becoming a responsible stakeholder in international society (Kissinger, 2011; Cox, 2012), others that its rapid economic expansion is the only thing standing against a global depression (Halper, 2010; Cox 2012), and many of them that if it continued to grow, it might soon be running Asia (Friedberg, 2011; Cox, 2012) or possibly even the world (Jacques, 2012; Cox, 2012).

As the world economy will be changing a lot over the next two or three decades, it is expected that the BRICs countries could become a much larger force in the world economy and could be larger than the G6 by 2039 . The role of China is becoming even more important, as it is predicted that China's economy could be larger than the USA by 2041 and larger than everyone else as early as 2016 .

According to the report China 2030: Building a Modern, Harmonious, and Creative Society, thanks to implementing new technologies, building modern infrastructure, investing in local people, and integrating with the world, considering local and interregional aspects; over the past three decades performance of China's economy has been impressive. In the following 15 to 20 years, China has not only the potential to be a modern, harmonious, and creative soci- 
ety, but also to become a high-income economy and the world's largest economy before 2030 .

As China currently is the largest outbound tourist generating country in the world, it is a fundamental key market for the world tourism industry (Rakotonanahary, 2014). Due to the increasing importance of tourism industry in China, the development of new habits and practices in behavior of the local population which are mostly reflected in cultural components and changing in current lifestyles of local people is evident. Leisure management's activities and programs are significantly gaining the importance in everyday life, and as a result of the increase of purchasing power of local people, a large percentage of Chinese people deciding to travel abroad. However, although the share of Chinese tourists in global tourist market is gradually increasing, it still cannot be claimed that this market segment is well recognized, examined and understood by creators of tourist offer at global market, what makes the potential of China quite limited. Faster economic growth of the middle class has led to the fact that people with middle and lower purchasing power traveling more and more, and that there is a huge interest of Chinese tourists for European countries as a tourist destinations. Which European countries will attract the largest number of Chinese tourists to a large extent depends on the knowing and familiarity with the specifics of Chinese tourist market. In that sense, it is necessary to clearly define the profile of tourists coming from China, their demographic characteristics, travel habits and motivation (Raspor et all., 2012).

In the next chapter short literature review about Chinese tourists' preferences will be presented.

\section{LITERATURE REVIEW}

As China has become one of the most important outbound tourist markets in the world during the last 20 years, there is a significant number of studies focuses on the Chinese outbound tourism, analyzing the profile of Chinese tourists, their demographic characteristics and specifics, their travel habits and motivations, their prefer- ences towards food, accommodation, types of travel arrangements and destinations, additional tourist offer, and purchasing preferences.

Chang, Kivela and Mak (2010) studied the preferences of Chinese tourists in relation to food. They have conducted a detailed analysis of the factors that have influenced the Chinese tourists in choosing foods at each destination. The study was conducted in Australia. They came to the conclusion that Chinese culture greatly influences Chinese tourists' choice of dishes for lunch. Also, they have concluded that Chinese tourists' food satisfaction affects the level of satisfaction with a complete tourist destination. In accordance with this conclusion, we can say that the Chinese culture influences the creation of a proper offer. It is no wonder why more new restaurants are specialized in Chinese cuisine. However, it should be borne in mind that the Chinese culture and their way of eating are highly specific, and that in order to meet their demands we should be well acquainted with their culture. Thus, for example: the Chinese drink hot water with a meal while in the West usually people drink cold water (Attract China, 2015).

Wong (2013) examines the purchasing preferences of Chinese tourists. Supporting research was carried out in casino tourism destinations. Author notes that there are differences in the purchasing preferences between men and women, and to a large extent it depends on the arrival place of Chinese tourists. As in the previous case, when we concluded that the satisfaction of food affects the total satisfaction of Chinese tourists, and in this case it was also found that satisfaction with the purchase affects the total satisfaction of Chinese tourists. Here is also found that gaming centers can easily grow to shopping destinations because Chinese tourists who go to visit the casinos spend a lot of money on shopping.

Numerous studies have shown that Chinese tourists like shopping tours and they spend a lot of money on purchases. Research conducted by $\mathrm{Xu}$ and McGehee (2012) confirms it. Specifically, these authors come to the conclusion that Chinese tourists in the United States are spending the most on watches, jewelry, health products and running shoes. It was also found 
that men are more satisfied with their purchase than women are, but also men and women agreed that it is necessary to engage more sales staff who speak the Chinese language, and that it would be desirable that the Chinese payment cards can be used in the USA. Summing up, the results of research made by these authors imply that Chinese tourists are generally satisfied with the purchase in the USA.

Liu et al. (2013) made an interesting analysis on the preferences of Chinese tourists. Specifically, the authors have based on the specific requirements of Chinese tourists, when they come to hotel accommodation. The results of their research show that Chinese tourists like to have tea in the room, buffet breakfast, and that the hotel has additional advantages such as hotels' attractive locations close to shopping centers and tourist attractions. The most preferred destinations are Europe and the USA. It is interesting that price is not crucial for making decisions where Chinese tourists want to go, but the visa regime is, in particular the USA. Although Chinese tourists like to plan trip on their own, as a more practical variant for them are group travel and package arrangements that have already been created. The famous hotel chains are already familiar with the specific preferences of Chinese tourists and there has been done very much to improve the service in hotels to this extremely fast-growing segment of the market, in order to be fully satisfied.

Packer, Ballantyne and Hughes (2014) make a comparison of Chinese tourists and tourists from Australia. The research results show that Chinese tourists love nature and its attractions but they are not animal lovers as they are feared, and also they are familiar with environmental issues. The research results of the mentioned authors are important for creating adequate tourist offer, which will be based on the flora and fauna for the Chinese market.

Skivalou and Filippidi (2015) study the trends and preferences of Chinese tourists in Greece. They used depth interview with Chinese tourists to identify push and pull factors of the destination. In the first place as the most significant factor is the cultural heritage, fol- lowed by rest and relaxation, but also there are the history of Greece, Greek hospitality, a good quality hotel services and Greek food. These findings are also a good basis for the creation of an adequate strategy for the development of tourism offer for the Chinese market.

Chen, Lehto and Tea (2013) examined the effects of vacation on the well-being of Chinese tourists. They come to the conclusion that the general physical condition after a trip by Chinese tourists does not change. The results of this study should be taken into consideration when a tourist trip has been created.

On the other hand, Pearce et al. (2013) examined the attitudes of Chinese tourists in Italy, using methods of informal interviews and poll. The research was conducted in Milan. They come to the conclusion that Chinese tourists spend a lot of time outdoors, that is to say they enjoy the observation of cultural and historical monuments that are critical and that it is a quite difficult to meet their expectations.

In order to develop the specialized tourist offer tailored for Chinese tourists and to establish the effective marketing strategies to attract a much larger number of them in Montenegro, all findings mentioned above should be considered.

\section{METHODOLOGY AND SAMPLE}

For the purpose of this scientific research, empirical survey was conducted in all three regions of Montenegro. The research was conducted in two periods: from January to December 2014, and from January to November 2015. The collected data were analyzed with Statistic Package for Social Science software v. 2.2. The questionnaires were filled in by Chinese tourists found in hotels, restaurants, bars etc. in several towns in Montenegro.

A closed questionnaire was prepared and it contained 36 questions. For determining Chinese tourists' opinion, Likert's scale - scaling method, measuring either positive or negative response was used. Respondents used values from 1 (the most negative answer) to 5 (the most positive answer). Descriptive statistical 
analysis was used as well. For the purpose of examination, questionnaires were translated into English and Chinese. Total number of examinees was 139 Chinese tourist in Montenegro, of whom 70 were examined in 2014 and 69 in 2015.

For the purpose of this paper it will be presented the results from the first period of research during the year of 2014, based on examination of 70 tourists from China. Furthermore, only the selected results which are in accordance with the main goal of the paper will be analyzed. Additionally, as at the moment collected

(a)

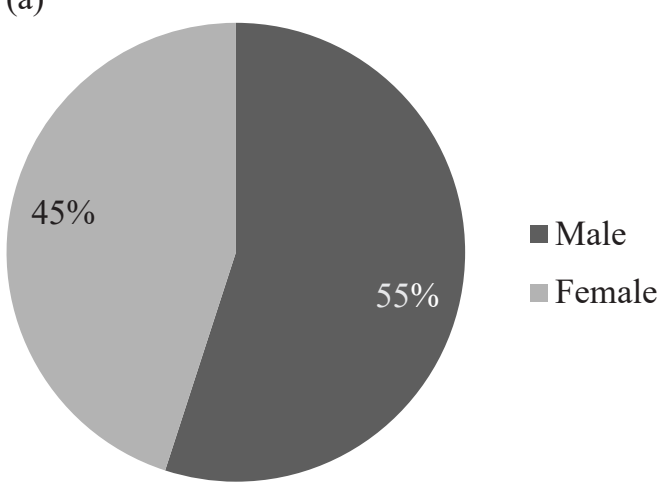

Graph 1. (a) Gender and (b) status structure

According to the examinees' gender structure there is a slightly smaller share of female, $45 \%$, compared to a larger share of male, $55 \%$. The data are still being analyzed, results based on examining the whole sample consisting of 139 Chinese tourists, during both 2014 and 2015, will be presented in future studies.

On the other side, during the same period several interviews with representatives of tourism sector in Montenegro were carried out, and those findings will also be presented in this paper.

The next charts illustrate the sample's gender and status structure, structure according to the part of China and type of the area where they live as well as yearly income structure.

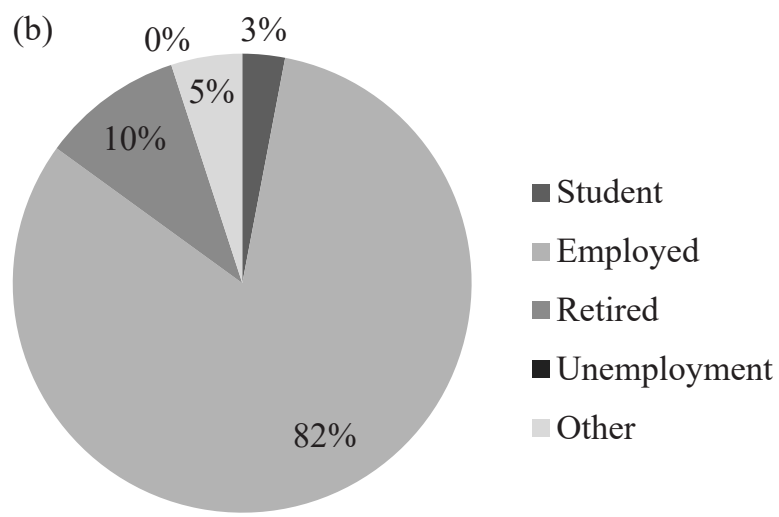

majority of the examinees were employed (82\%), then retired (10\%), students (3\%) and other $(5 \%)$. There were no unemployed Chinese tourists.
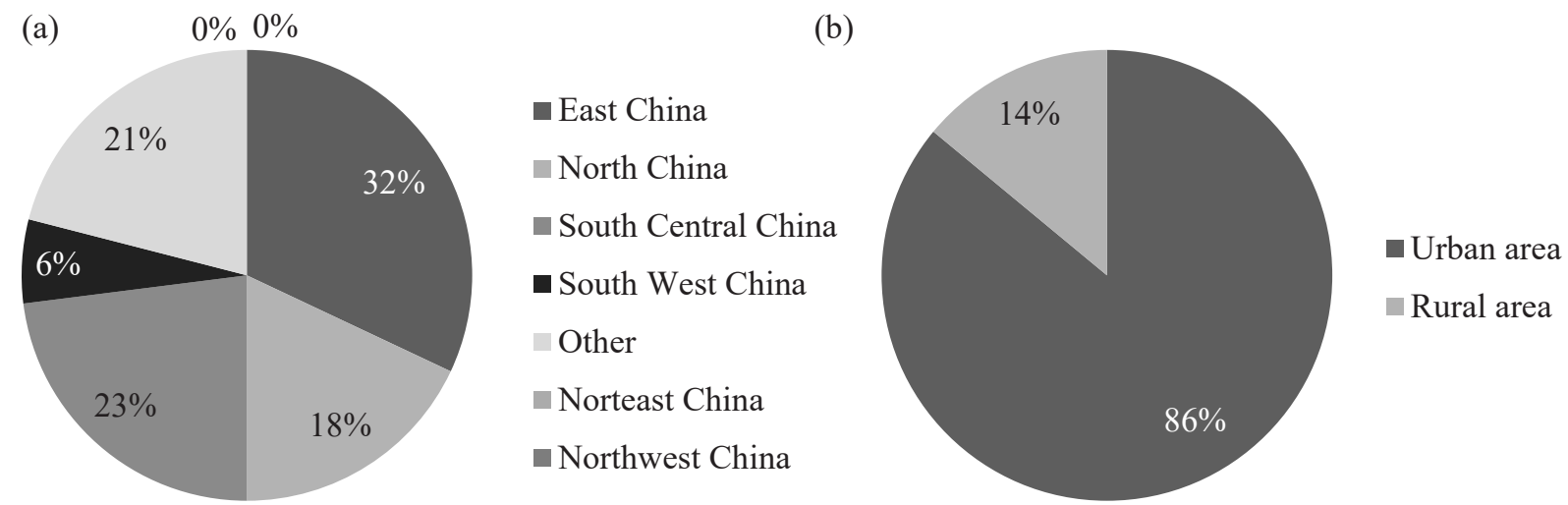

Graph 2. (a) Part of China and (b) type of area

The examinees were mostly from East China (32\%), South Central China (23\%), then from North China (18\%), South West China $(6 \%)$ and other parts of the country
$(21 \%)$. The number of the examinees who live in urban areas was much larger (86\%) from the number of those who live in rural areas $(14 \%)$. 


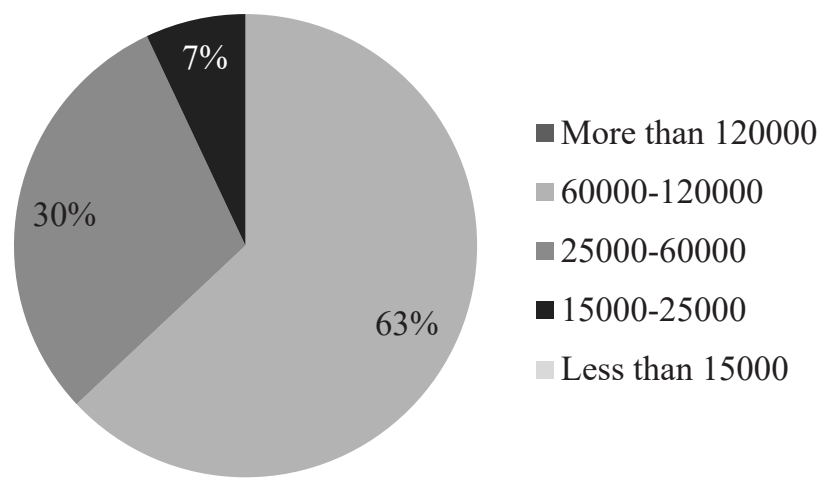

Chart 3. Structure according to income

The number of the examinees with income from 60000 to $120000 \mathrm{RMB}$ was the largest (63\%), then with income from 25000 to 60000 RMB (30\%) and the smallest number with income less from 15000 to $25000 \mathrm{RMB}(7 \%)$.

\section{RESULTS}

In the following part of the paper it will be presented the most important results of this empirical study, consisting of demographic characteristics and attitudes of Chinese tourists towards the tourist offer of Montenegro.

\section{Demographic characteristics of Chinese tourists}

According to sample structure it could be concluded that, depending on gender, Chi- nese tourists both male and female equally visiting Montenegro. The most of tourists from China who visiting Montenegro according to status are employed people, and according to the part of China, they are the most often coming from East and South Central China. The majority of Chinese tourists lives in urban areas of China and belongs to the higher middle class.

\section{Chinese tourists' attitudes towards the tourist offer of Montenegro}

When it is about the source of information regarding Montenegro, according to findings, the most of Chinese tourists has heard about Montenegro from travel agencies, two-fifths of all number of them.

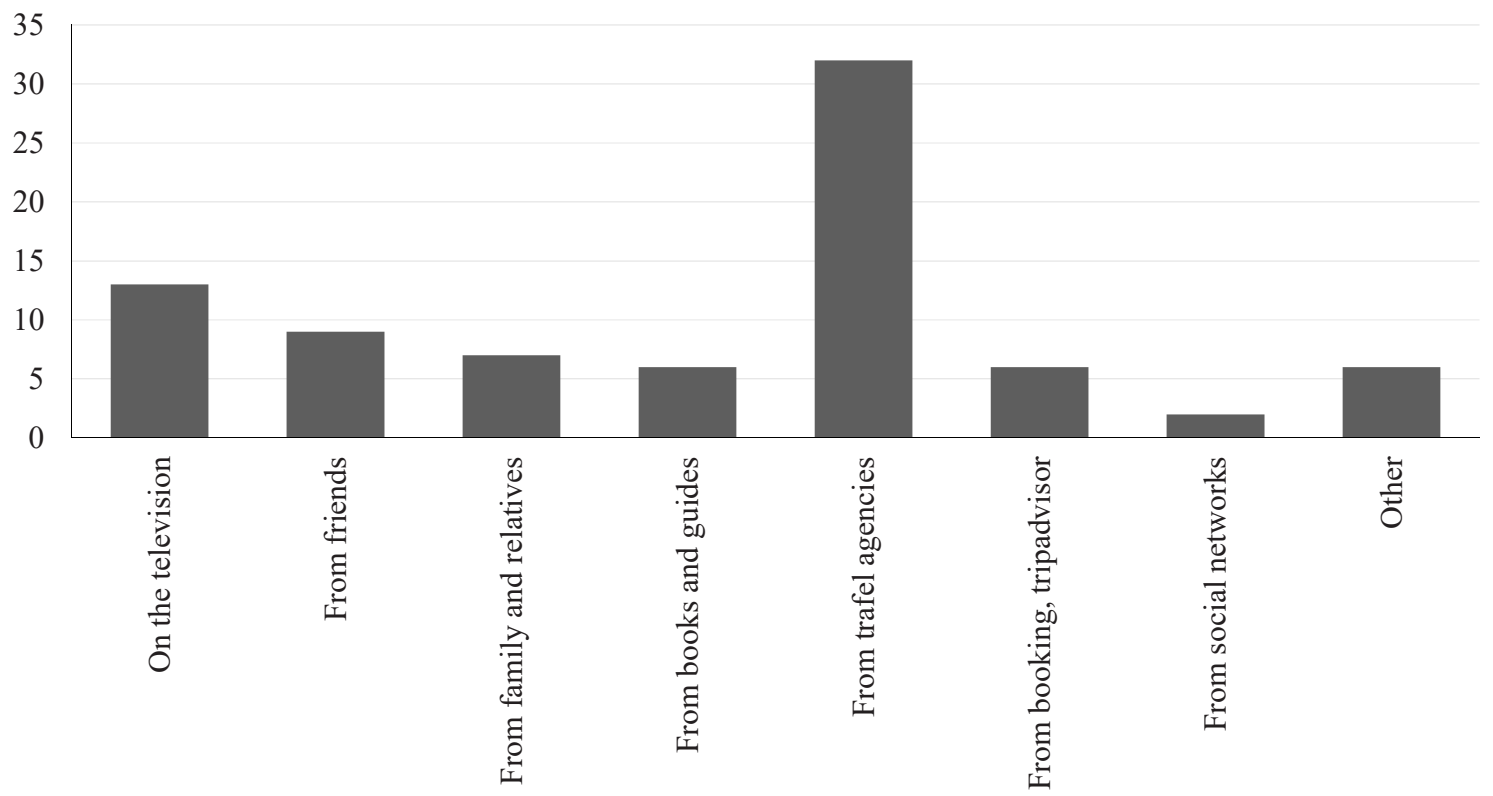

Graph 4. Structure according to source of information about Montenegro - Where have you heard about Montenegro? 
One-fifth of all respondents has heard about Montenegro from other people: from their friends $(11 \%)$, and family and relatives $(9 \%)$, while the television as a source of information was used by $16 \%$ of Chinese tourists. When finding information about Montenegro, the same number of tourists from China was using books and guides as well as websites www.booking.com and www.tripadvisor.com (7\%). The smallest number of them was using social networks for exploring the tourist offer of Montenegro, only 3\%.

From these findings it could be concluded that in the promotion of Montenegro among
Chinese tourists the most important role have travel agencies, but that the significance of "the word-of-mouth advertising" is high as well.

More than four of ten Chinese tourists visited Podgorica, the capital of Montenegro, and almost the same percentage of them visited coast side, including the most popular and most visited coastal towns: Budva, Kotor and Ulcinj. Same number of tourists from China visited National Park Skadarsko jezero and National Park Biogradska gora, almost one tenth of total number, and slightly smaller share of tourists visited National Park Lovćen and National Park Durmitor.

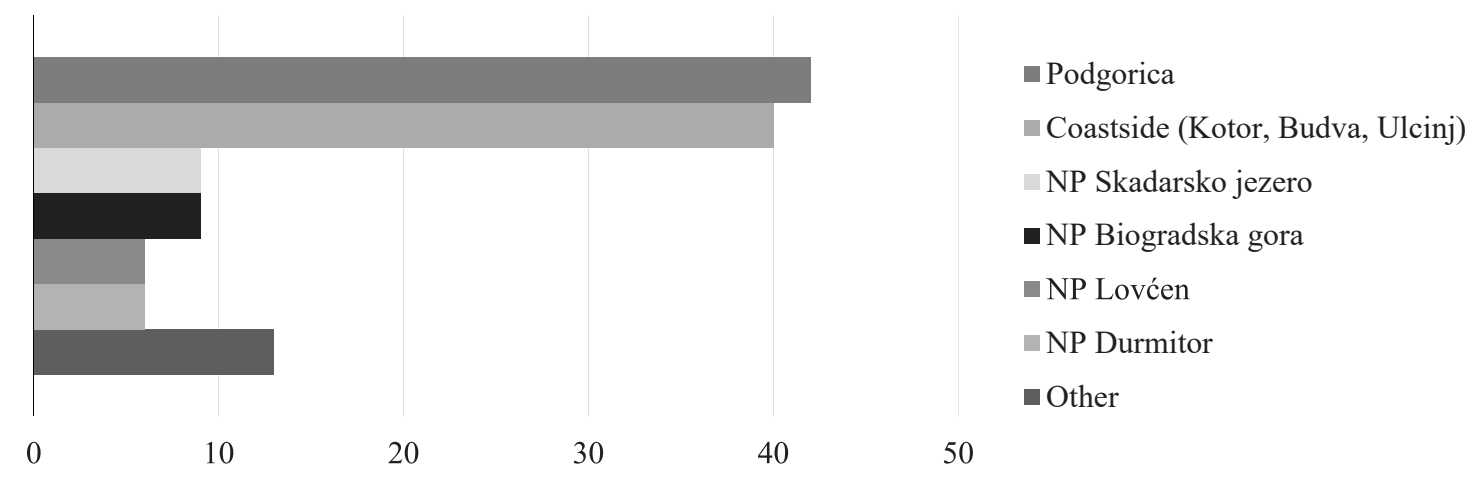

Graph 5. Structure according to visited places - Which places did you visit?

Apart from mentioned regions, $13 \%$ of Chinese tourists visited also some other destinations in Montenegro, so it could be concluded that almost all important tourist places in Montenegro are visited by Chinese tourists in certain percentage.

More than six-tenth of Chinese tourists during their trip spent in Montenegro two to three day, while the duration of stay for one-third of them was less than two days. There were no Chinese tourists who spent more than three days in Montenegro. At the same time, according to official statistics in Montenegro, average stay of Chinese tourists in 2014 was 1,82 days and in 2015 it was 1,36 days, so the statistical data are in accordance with findings of the our research.

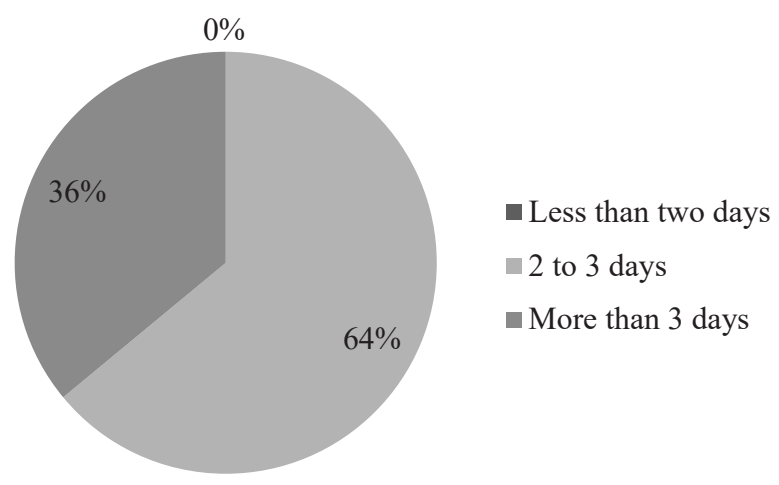

Graph 6. Duration of stay - How many days did you stay in Montegro? 
It is evident that the duration of stay of Chinese tourists in Montenegro is very short. This is caused by the fact that Chinese tourists, as tourists from long distance market, when visiting one region of the world, plan to visit at the same time several different countries during that one trip.
When we asked Chinese tourists for their opinion about specific segments of the tourist offer of Montenegro, they used values from 1 (the most negative answer - I like the least) to 5 (the most positive answer - I like the most).

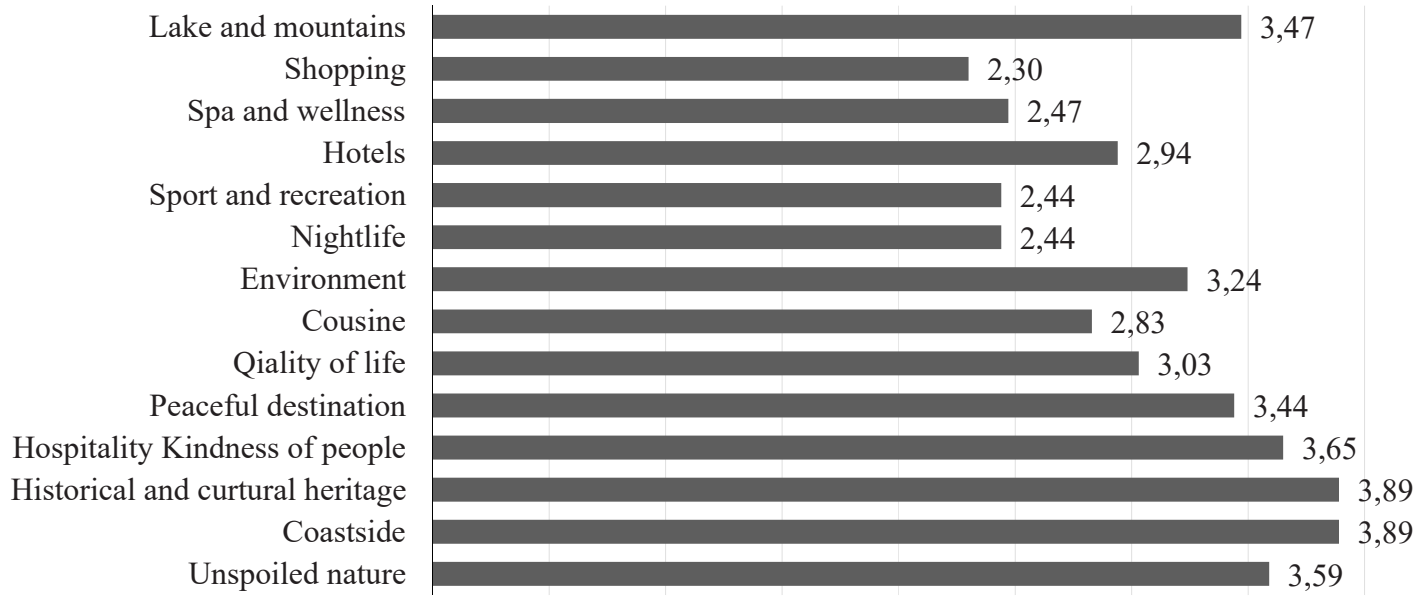

Graph 7. Opinion about segments of tourist offer in Montenegro - What did you like the most when you visited Montenegro? (average rate - 1:the least, 5- the most)

Among all segments of tourist offer in Montenegro, Chinese tourists gave the highest marks to the coast side and to the historical and cultural heritage; to both of them they gave high average mark - 3.89. Very good marks they gave to the hospitality and kindness of the local people (3.65), then to the unspoiled nature (3.59), the lakes and mountains (3.47), the peacefulness of the destination (3.44), and the environment (3.24). The quality of life (3.03), hotels (2.94), and cuisine (2.83) were evaluated with moderately good marks, and the lowest marks by Chinese tourists were given to spa and wellness (2.47), sport and recreation (2.44), night life (2.44), and shopping (2.30).

It could be concluded that Chinese tourists are very satisfied with the natural and cultural resources and as well with the hospitality of local people in Montenegro. They are relatively satisfied with the accommodation facilities and food and beverage offer available at our destination. With additional tourist offer including spa and wellness, sport and recreation and as well night life and shopping, Chinese tourist are not satisfied enough.

In addition, it is important to point out that especially those Chinese tourists who were well informed about Montenegro and its natural, cultural and supporting resources, before their arrival are not very satisfied with tourist offer of this destination.

When it comes to the form in which Chinese tourists would like to visit Montenegro again in the future, different findings are identified. The most of Chinese tourists would like to visit Montenegro as a part of tourist package with the Western European countries such are: Italy, France, Germany, Austria and Switzerland, but especially with Mediterranean countries Italy and France. A much smaller number of tourists would visit Montenegro again together with all other countries of Former Yugoslavia and there is the smallest share of them who would like to visit it as a single tourist destination. 


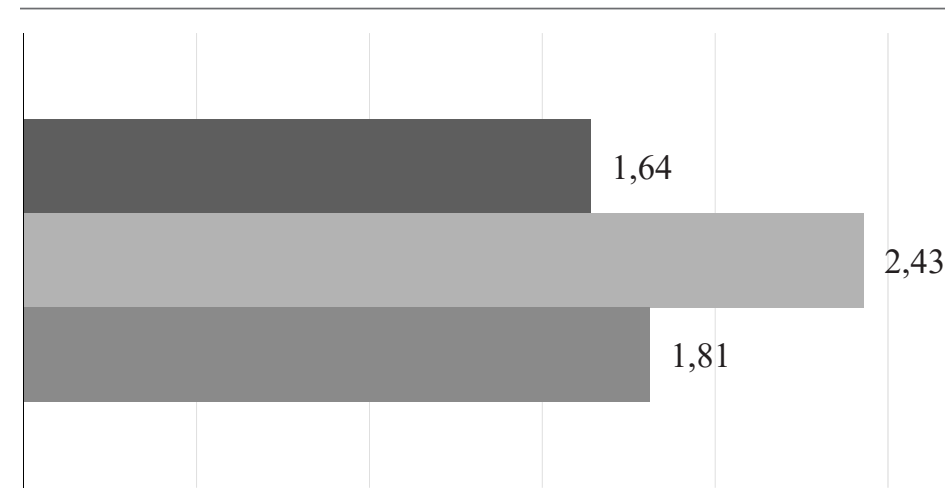

\author{
As a single tourist destination \\ Tourist package with the West \\ Europen countries (Italy, France, \\ Germany, Austria, Switzerland) \\ - Tourist package with all other \\ countries of Former Yugoslavia
}

Graph 8. Form of future visit of Montenegro - In which form would you like to visit Montenegro in the future? (1-the least, 5 -the most)

Based on these results, it could be concluded that Chinese tourists are mostly interested in visiting Montenegro as a part of tourist package with Mediterranean and Western European countries, while they are less interested in visiting it together with countries of Former Yugoslavia and as a single destination. These finding were expected, bearing in mind that Chinese tourists when traveling always visit several destinations during a single trip.

From the other side, according to results of the interviews carried out with managers of tourist agencies, tourism organizations and hotels in Montenegro, it could be ascertained that the most visited place in Montenegro by Chinese tourists at the moment is Kotor, coastal town located at the Boka Bay, one of the most indented parts of the Adriatic Sea. Bay of Kotor along with the old town is a world heritage site, announced officially Natural, Cultural and Historical Region by UNESCO in 1979. The most of Chinese tourists visit Kotor as a part of their cruise tours in the Mediterranean Sea. They usually come there in organized groups, but stay unfortunately not more than few hours. Visitors are attracted by both the natural beauty of the Bay of Kotor and by the old town, one of the best preserved medieval old towns in the Adriatic.

Additionally, groups of Chinese tourists come to Montenegro as a part of their tours organized in the region of Former Yugoslavia, especially Macedonian-Montenegrin tours, during which they spend 3 days in Montenegro, visiting Podgorica - capital, Coastline and NP Durmitor in the mountain region.

There is also a small number of individual Chinese tourists, who are usually business people.

\section{CHINESE TOURIST ARRIVALS AND OVERNIGHT STAYS IN MONTENEGRO}

Chinese tourists, within official statistics in Montenegro, were counted in the group "Other countries" until the beginning of 2014. Therefore, data about Chinese tourist arrivals and overnight stays in Montenegro exist only from 2014.

All foreign tourists in Montenegro in 2014 realized 1,350,297 arrivals, while they made $8,596,656$ overnight stays. Chinese tourist arrivals and overnight stays in Montenegro in 2014 are presented in the next table.

Table 1.

Chinese tourist arrivals and overnight stays in Montenegro in 2014

\begin{tabular}{lcccc}
\hline Month/2014 & Arrivals & $\begin{array}{c}\text { Structure in \% in } \\
\text { foreign tourists }\end{array}$ & Overnight stays & $\begin{array}{c}\text { Structure in \% in } \\
\text { foreign tourists }\end{array}$ \\
\hline January & 243 & 2.2 & 595 & 1.4 \\
\hline February & 340 & 2.7 & 418 & 1.0 \\
\hline
\end{tabular}

Note: Table 1 continued on next page 


\begin{tabular}{lcccc}
\hline March & 552 & 3.1 & 583 & 0.9 \\
\hline April & 357 & 1.2 & 414 & 0.4 \\
\hline May & 678 & 0.8 & 1,368 & 0.4 \\
\hline June & 783 & 0.5 & 1,130 & 0.1 \\
\hline July & 952 & 0.3 & 2,317 & 0.1 \\
\hline August & 1,068 & 0.2 & 3,191 & 0.1 \\
\hline September & 1,138 & 0.6 & 1,677 & 0.1 \\
\hline October & 1,163 & 2.9 & 1,335 & 0.8 \\
\hline November & 390 & 2.3 & 608 & 1.0 \\
\hline December & 268 & 1.8 & 796 & 1.5 \\
\hline Total & 7,932 & 0.59 & 14,432 & 0.17 \\
\hline
\end{tabular}

Source: Monstat, 2015

According to official statistics in Montenegro in the first half of 2014, tourists from China (including Hong Kong) realized 0.63\% of foreign tourist arrivals and $0.18 \%$ of overnight stays of foreign tourists. They stayed for 1.75 days in Montenegro, which is 3.7 times shorter than average stay.

If we analyze the data for complete year 2014, we can find similar results. Total number of Chinese tourist arrivals in 2014 was 7,932 , which makes $0.59 \%$ of foreign tourist arrivals. When it is about of overnight stays, Chinese tourists realized 14,432, which makes $0.17 \%$ of foreign tourist overnight stays in Montenegro. They stayed for 1.82 days in Montenegro, while the average tourist stay in 2014 in Montenegro was 6.37 days.

During 2014, the largest number of Chinese tourists visited Montenegro in October, September and August, and the smallest number of them visited Montenegro in January,
December and February. However, share of Chinese tourist arrivals in 2014, comparing to foreign tourist arrivals, was on the highest level in March (3.1\%), October (2.9\%) and February (2.7\%) and on the lowest in August $(0.2 \%)$, July $(0.3 \%)$ and June $(0.5 \%)$.

The largest number of overnight stays of Chinese tourists was realized in August, July and September, but at the same time, their percentage in total overnight stays of foreign tourists was the smallest in these mounts. The highest share of Chinese tourist overnights stays was realized in January and December. Those results are caused by the fact that the highest tourist demand in Montenegro is in the summer season.

Furthermore, in Montenegro in 2015, all foreign tourists realized 1,559,924 arrivals, while they made 10,307,371 overnight stays. Data about Chinese tourist arrivals and overnight stays in 2015 are presented in the next table.

Table 2.

Chinese tourist arrivals and overnight stays in Montenegro in 2015

\begin{tabular}{lcccc}
\hline Month/2014 & Arrivals & $\begin{array}{c}\text { Structure in \% in } \\
\text { foreign tourists }\end{array}$ & $\begin{array}{c}\text { Overnight stays } \\
\text { foreign tourists }\end{array}$ & $\begin{array}{c}\text { Structure in \% in } \\
\text { fored }\end{array}$ \\
\hline January & 65 & 0.5 & 109 & 0.2 \\
\hline February & 249 & 1.5 & 283 & 0.5 \\
\hline March & 446 & 2.4 & 627 & 0.9 \\
\hline April & 826 & 2.2 & 948 & 0.8 \\
\hline May & 2,494 & 2.9 & 3,232 & 0.8 \\
\hline June & 1,878 & 1.2 & 3,049 & 0.3 \\
\hline
\end{tabular}

Note: Table 1 continued on next page 


\begin{tabular}{lcccc}
\hline July & 1,225 & 0.3 & 1,852 & 0.1 \\
\hline August & 988 & 0.2 & 1,473 & 0.0 \\
\hline September & 1,919 & 0.9 & 2,476 & 0.2 \\
\hline October & 2,206 & 5.3 & 2,616 & 1.4 \\
\hline November & 602 & 3.1 & 855 & 1.0 \\
\hline December & 464 & 2.5 & 650 & 1.0 \\
\hline Total & 13,362 & 0.86 & 18,170 & 0.18 \\
\hline
\end{tabular}

Source: Monstat, 2015

In Montenegro in 2015, tourists from China (including Hong Kong) realized 13,362 arrivals, which makes $0.86 \%$ of foreign tourist arrivals and 18,170 overnight stays, which makes $0.18 \%$ of overnight stays of all foreign tourists. They stayed for 1.36 days in Montenegro, which is 4.9 times shorter than average stay (6.61 days).

During 2015, the largest number of Chinese tourist visited Montenegro in May, October, September and June, and at the same time, the largest number of overnight stays of Chinese tourists was made in same months of the year, in this order: May, June, October and September. On the other hand, share of Chinese tourist arriv- als in 2015 was on the highest level in October (5.3\%), November (3.1\%) and May (2.9\%), and their share in all foreign tourist overnight stays was the highest is in October (1.4\%), November $(1 \%)$ and December (1\%), which is caused by the fact that these months do not belong to the most visited period of the year in Montenegro.

Moreover, if we compare tourist arrivals and overnight stays in Montenegro in 2014 to data from 2015 , it could be noticed the increase in number of both all foreign tourists and Chinese tourists.

Tourist arrivals and overnights in 2014 and 2015 are presented in the next table.

Table 3.

Foreign and Chinese tourist arrivals and overnight stays in Montenegro in 2014 and 2015

\begin{tabular}{|c|c|c|c|c|c|}
\hline & & $\begin{array}{c}\text { Tourist } \\
\text { Arrivals }\end{array}$ & $\begin{array}{c}\text { Tourist } \\
\text { Overnights }\end{array}$ & $\begin{array}{c}\text { Foreign } \\
\text { tourists' } \\
\text { overnights }\end{array}$ & $\begin{array}{c}\text { Chinese } \\
\text { tourists' } \\
\text { overnights }\end{array}$ \\
\hline \multirow{3}{*}{2014} & Foreign tourists & $1,350,297$ & $8,596,656$ & \multirow{3}{*}{6.37} & \multirow{3}{*}{1.82} \\
\hline & Chinese tourists & 7,932 & 14,432 & & \\
\hline & Chinese tourists' share & 0,59 & 0,17 & & \\
\hline \multirow{3}{*}{2015} & Foreign tourists & $1,559,924$ & $10,307,371$ & \multirow{3}{*}{6.61} & \multirow{3}{*}{1.36} \\
\hline & Chinese tourists & 13,362 & 18,170 & & \\
\hline & Chinese tourists 'share & 0.86 & 0.18 & & \\
\hline
\end{tabular}

Source: Monstat, 2016

The number of foreign tourists in Montenegro in 2015, compared to previous year, increased from 1,350,297 to $1,559,924$ tourist arrivals. At the same time, foreign tourists made $8,596,656$ overnight stays in 2014 , and that number also increased to $10,307,371$ overnight stays in 2015.

Chinese tourists in Montenegro realized 7,932 tourist arrivals in 2014, while in 2015 they realized 13,362 , which is $68.45 \%$ of tourist arrivals more. The number of Chinese tourist overnight stays also increased from 14,432 in 2014 to 18,170 in 2015 , which is $25.90 \%$ more than in the year before.

The share of tourists from China in foreign tourist arrivals has increased as well, having in mind that in 2014 it was $0.59 \%$ and in 2015 it was $0.86 \%$, while their share in foreign tourist 
overnight stays was almost the same, in 2014 it was $0.17 \%$ and in 2015 it was $0.18 \%$.

While the duration of Chinese tourist stay in Montenegro, comparing to average foreign tourist stay, was much shorter in $2014,1.82$ days to 6.37 days, the difference in 2015 is even larger. Actually, the duration of stay of Chinese tourists decreased from 1.82 to only 1.36 days, while at the same time the average foreign tourist stay increased to 6.61 days.

Even though the share of Chinese tourist arrivals and overnight stays in Montenegro in total number of foreign tourists is rather insignificant, the fact that certain increase in the number of Chinese tourist arrivals is evident in 2015 comparing to 2014 is encouraging data. Additionally, a very important step in approach towards Chinese tourist market is made by starting with statistical recording of Chinese tourists in the framework of official statistics in Montenegro, since the beginning of 2014.

\section{CONCLUSION}

By critical observation and examination of the relevant literature, collecting and analyzing the official statistical data, conducting the interviews with representatives of tourism industry in Montenegro, and especially by analyzing the findings of the empirical research carried out among Chinese tourists in Montenegro, we came to the significant conclusions regarding the opportunities for tourism of Montenegro at the Chinese tourist market.

Chinese tourists visit Montenegro rather in the organized groups than as individual guests, which is mostly the case of business people. When it is about the organized groups, they are coming in Montenegro mostly by foreign tourist agencies and tour operators, as there are no sufficient domestic operators which are dealing with Chinese tourist market. Additionally, a certain number of Chinese tourists visit Montenegro only as a part of their cruise tours in the Mediterranean Sea.

The share of Chinese tourists in Montenegro in 2014 was only $0.58 \%$ of all foreign tourist arrivals and $0.17 \%$ of all foreign tourist overnight stays, and in 2015 it was $0.86 \%$ of all foreign tourist arrivals and $0.18 \%$ of all foreign tourist overnight stays. Even though the number of Chinese tourists who were visiting Montenegro during 2014 and 2015 is not significant, from the angle of prospective development of Chinese tourist market in Montenegro, it is very important that this segment of tourists is characterized by gradual increase, especially in tourist arrivals, while the duration of their stay still is not on the appropriate level. Actually, in 2015 considerable decrease in the duration of Chinese tourist stay was registered, and therefore their stay was almost 5 times shorter than average stay of all foreign tourists. In that sense, it is necessary to create the tourist product of Montenegro which will be more appealing to Chinese tourists in order to make them stay longer at our destination.

In addition, the very important fact is that from the beginning of 2014 in Montenegro there are official data about Chinese tourist arrivals and overnight stays, having in mind that in the previous period it was not the case, as the Chinese tourists were counted under the group of "other tourists". It was the great obstacle for analysis and research of Chinese tourists in Montenegro, which did not allow creating relevant conclusions and establishing appropriate strategies in the past period.

From the other side, relatively encouraging data were obtained from the empirical research on the Chinese tourists' attitudes towards tourist offer of Montenegro. Having in mind that examined Chinese tourists were not satisfied enough with the additional tourist offer including spa and wellness, sport and recreation, night life and shopping, it is necessary to improve, expand and upgrade these segments of the offer, especially considering the importance of shopping as an additional attraction within tourist travel for Chinese tourists. Even though they were relatively satisfied with accommodation facilities and cuisine in Montenegro, we should not forget that Chinese tourists prefer to eat and drink their local food and beverage even during traveling to different tourist destinations 
around the world, so Chinese cuisine must be indispensable part of food and beverage offer in Montenegro. Very important finding of this research is that Chinese tourists were very satisfied with the natural and cultural resources and with the hospitality of local people in Montenegro, as these segments of tourist offer are actually the main resources of one tourist destination and the most important motives for majority of tourists to visit a certain destination. However, those Chinese tourists, who were well informed about the tourist offer of Montenegro in advance, before their trip, gave lower marks about the offer, than those tourists who were not informed about Montenegro at all. In that sense, the promotional strategy of Montenegro at the tourist market of China should be considered and analyzed in detail.

Majority of examined Chinese tourists prefer to visit Montenegro in future as a part of the tourist package with some other countries, predominantly with Mediterranean and Western European countries, as they during their vacation always visit several destinations at the same time. Given that the little interest by Chinese tourists was expressed for tourist package consisting of countries of Former Yugoslavia, their adequate and more intensive promotion at the Chinese market should be carried out.

In order to adapt to this long-distance tourist market, whose specific characteristics we still do not know good enough, it would be necessary to become more familiar with Chinese culture and to try to understand it in a larger extend. Chinese tourists' characteristics, travel habits and their decisions for the travel destination should be much more analyzed by representatives of tourism industry in Montenegro, and, based on that, the tourist product of Montenegro should be tailored to their special requirements and needs. It would be of a great importance that employees in tourism sector in Montenegro, especially tour guides, do speak at least basic Chinese language, and that in hotels and public places there are Chinese signage, as this segment of foreign tourists appreciates that very much. It is recom- mended that Chinese currency RMB could be convertible in Montenegro and that Chinese credit cards could be used in our country, especially having in mind the significant role of purchasing for Chinese tourists during travelling abroad. Establishing much better airline connections between Montenegro and China is essential step in providing a larger number of Chinese tourists. In order to create the effective marketing policy and attract more Chinese tourists, it would be very important that advertising approaches of Montenegro as a tourist destination is improved and adapted to specific characteristics and expectations of this tourist segment, and that direct and specialized tourism promotion at the Chinese market is carried out.

As Chinese tourists are long distance tourists who usually visit several destinations during one trip, to satisfy their needs, it is necessary to develop an integrated and sustainable tourist offer of certain region of the world, in this case of the Mediterranean or Adriatic-Ionian region. In that sense, intensive cooperation between tourist destinations of this part of the Europe would be essential for the successful common positioning on the Chinese tourist market. Only after the total adjustment of Montenegro tourist offer to the Chinese tourists' preferences, we could say that Montenegro is completely ready for intensive acceptance of Chinese tourists.

\section{LITERATURE}

Arlt, W. G, (2016). China Information Day Conference. Budapest, March 3, 2016.

Barnett, S. (2011). China: Economic Development and Outlook. Research Institute of Economy, Trade \& Industry, IAA, http:// www.rieti.go.jp/en/.

Bofulin, M., Raspor, A., Stranjančević, A., Bulatović, I. and Lacmanović, D. (2016). Small destinations in large tourism market: the analysis of Western Balkan countries and the Chinese outbound tourism. International Scientific Journal, 8, p. 130-143. 
Chang, R. C., Kivela, J. and Mak, A. H. (2010). Food preferences of Chinese tourists. Annals of Tourism Research, 37, p. 989-1011.

Chen, Y., Lehto, X. Y. and Cai, L. (2013). Vacation and well-being: a study of Chinese tourists. Annals of Tourism Research, 42, p. 284-310.

Cox, M. (2012). Power Shifts, Economic Change and the Decline of the West?. International Relations, 26, p. 369-388.

Friedberg, A. (2011). A Contest for Supremacy: China, America and the Struggle for the Mastery of Asia. New York: W.W. Norton.

Halper, S. (2010). The Beijing Consensus: How China's Authoritarian Model Will Dominate the 21st Century. New York: Basic Books.

Hofman, B. (2016). China's medium-term Outlook: 2016-2020, Regional Agenda: Geo-economics with Chinese Characteristics: How China's economic might is reshaping world politics. World Economic Forum Geneva.

Jacques, M. (2012). When China Rules the World: The Rise of the Middle Kingdom and the End of the Western World. London: Penguin/Allen Lane.

Kissinger, H. (2011). On China. New York: Penguin.

Lacmanović, D. et. all. (2013). Project proposal: The development of integrated offer of sustainable tourism of Slovenia and Montenergo to the market modal East (Chine). Faculty of Tourism Bar.

Lim, C. and Pan, G. W. (2003). An Econometric Analysis of Inbound Tourism for China. International Congress on Modeling and Simulation 3.

Liu, P., Zhou, L., and Chandnani, R. (2013). Preferences and attitudes of Chinese outbound travelers: The hotel industry welcomes a growing market segment. Cornell Hospitality Report, 13, p. 6-15.
Packer, J., Ballantyne, R., and Hughes, K. (2014). Chinese and Australian tourists' attitudes to nature, animals and environmental issues: Implications for the design of nature-based tourism experiences. Tourism Management, 44, p. 101-107.

Pearce, P. L., Wu, M. Y., De Carlo, M. and Rossi, A. (2013). Contemporary experiences of Chinese tourists in Italy: An onsite analysis in Milan. Tourism Management Perspectives, 7, p. 34-37.

Purushothaman, R. and Wilson, D. (2003). Dreaming with BRIC's: The Path to 2050. Global Economics Paper, 99, p. 1-24.

Rakotonanahary, F., N. (2014). Profile of Chinese Outbound Tourists: Characteristics and Expenditures. American Journal of Tourism Management, 3, p. 17-31.

Raspor, A., Kobal, T. and Rodič, B. (2012). Chinese tourists - are they an opportunity for the Slovene and Croatian tourist industry?. Tourism and Hospitality Management, 18, p. 111-125.

Skivalou, M. and Filippidi, E. (2015). Chinese tourism: Development and prospects for Greece. Tourism and Hospitality Research, 21.

Wong, I. K. A. (2013). Mainland Chinese shopping preferences and service perceptions in the Asian gaming destination of Macau. Journal of Vacation Marketing, 19, p. 239-251.

$\mathrm{Xu}$, Y., and McGehee, N. G. (2012). Shopping behavior of Chinese tourists visiting the United States: Letting the shoppers do the talking. Tourism Management, 33, p. 427-430.

World Bank and the Development Research Center of the State Council, P. R. China. (2013). China 2030: Building a Modern, Harmonious, and Creative Society. Washington, DC: World Bank. 